\title{
Pulling Data From Multiple Websites TO IDENTIFY BEST DEALS ON AUCTION WEBSITES
}

\author{
GuruSharmila $\mathrm{S}^{1}$ Arul Amalraj A ${ }^{2}$ Subalakshmi $\mathrm{K}^{3}$ \\ ${ }^{1}$ Department of Computer Application,Francis Xavier Engineering \\ College, Tamil Nadu, Tirunelveli \\ ${ }^{2}$ AP/Department of Computer Application,Francis Xavier Engineering \\ College,Tamil Nadu, Tirunelveli \\ ${ }^{3}$ Department of Computer Application,Francis Xavier Engineering \\ College, Tamil Nadu, Tirunelveli
}

\begin{abstract}
Robotic process automation(RPA)is an emerging tool of automation technology based on notion of software robots or Artificial intelligence(AI). If the customer wants to buy a Bluetooth speaker. He will go to flip kart and search the product. and see the prices as expensive. He will buy it .But the same product is cheaper in Amazon. So our project will give the best product based on the best price and best rating.
\end{abstract}

\section{KEYWORDS}

$R P A, B P A, A I, E N I A C, S P$

\section{INTRODUCTION}

Robotic Process Automation (RPA) is being leveraged by many businesses around the world in a wide variety of sectors to provide a vital competitive advantage in business process automation. IT Automation is enabled by software including APIs, scripts, jobs, schedulers, programs, events and a broad range of automation tools. With the advent of Cloud Computing, resources are exposed by APIs and accessible in real-time.

"Watson is creating a new partnership between people and computers that enhance, scales and accelerates human expertise "Way back in 1943, the ENIAC, the computing machine was invented by J.Presper Eckert and John Mauchly at the University of Pennsylvania and was not completed until 1946. Some people say that abacus was the first computing machine. This is how the computing era started in decades back. Like a chameleon, the computing technology wearing different colors in terms of hardware like desktops, servers, laptops, mobiles and now entering into "rolltops". In addition to this, abundant software developments happened in terms of operating systems, applications, utilities and computing capabilities at the networking edge level with high bandwidth. Further, the organizational applications also stepped into many folds including punch cards, spreadsheets, office applications, management information systems and enterprise resource planning to assist in business applications. Nowadays the business operations are leapfrogging into the new technological land the so-called "Robotic Process Automation. 
The way Companies do their business, the way people do official work as well as the public daily life is going to be drastically assisted by new hardware, software technologies along with smart devices. The lifestyles of human being are changing across the due to global collaborations, multinational businesses, new IT/ITes advancements with RPA technology. Along with the existing new technologies functional in the human life Viz. Internet of Things, Big Data Analytics, Deep Learning, Artificial Intelligence, Machine Learning and other allied technologies, RPA is becoming one of the noteworthy disrupting technology.

\section{Architecture Diagram}

\section{RPAARCHITECTURE}

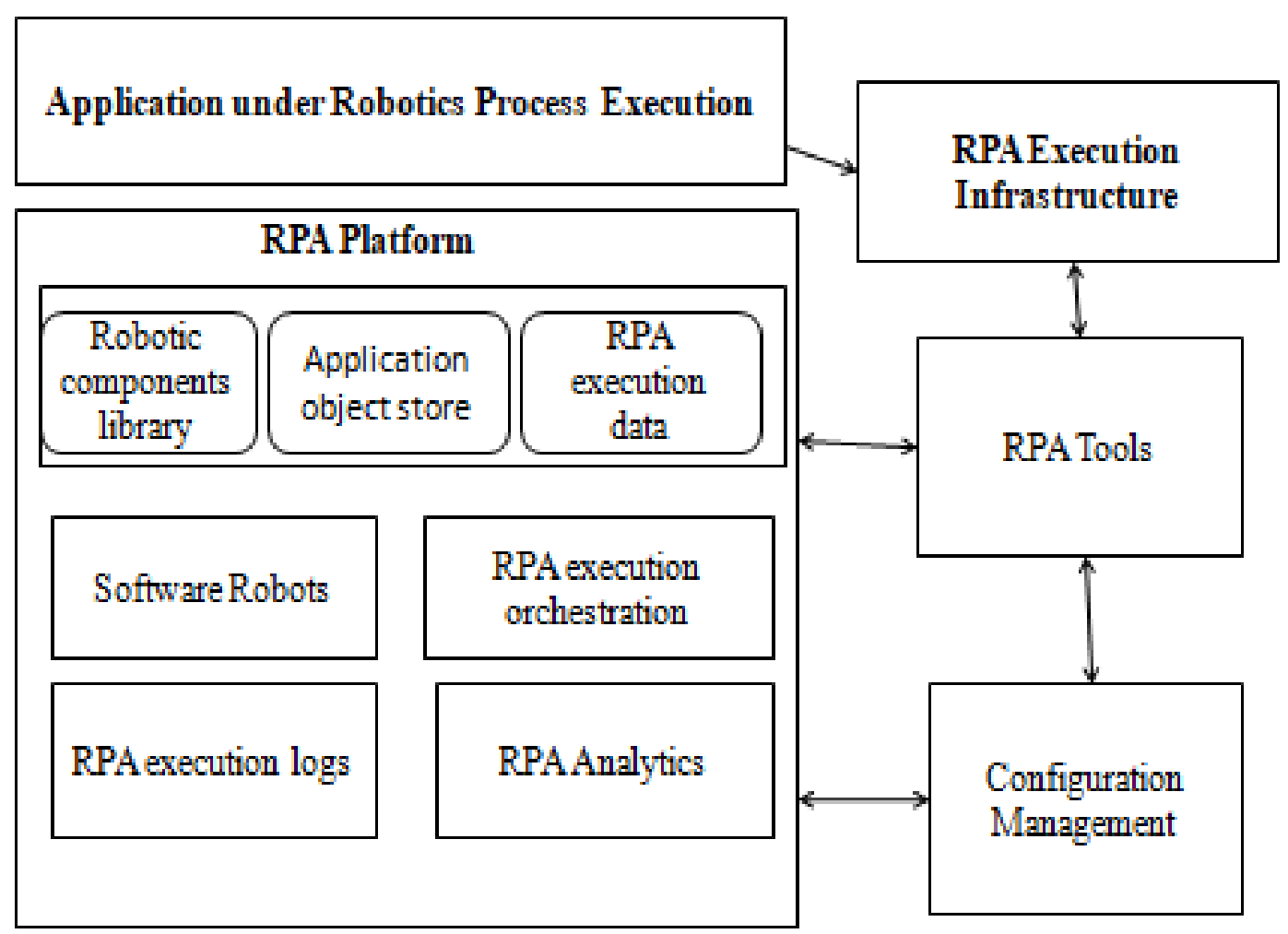

Figure 1 Architecture diagram

\section{Problem Statement}

\section{Modules}

\section{Economic}

Economic feasibility is to check out the project in the view that whether it is financially satisfies the client as well as developers. In this project the secure framework helps to increase the security and reduce the cost. This economic feasibility helps us to ensure the budget of the project is reduced. It is essential. 


\section{Technical}

Technical feasibility helps to know about the project satisfies the technical requirement. Technical feasibility centers on the existing computer system and to what extent, it can support the proposed addition.

\section{Social}

An estimate is made of how strong are action the user is likely to have towards the development this software and how it is used successfully in real time situation. It requires less man power and thus it is socially feasible.

\section{EXPERIMENT AND RESULTS}

\section{Output Screen}

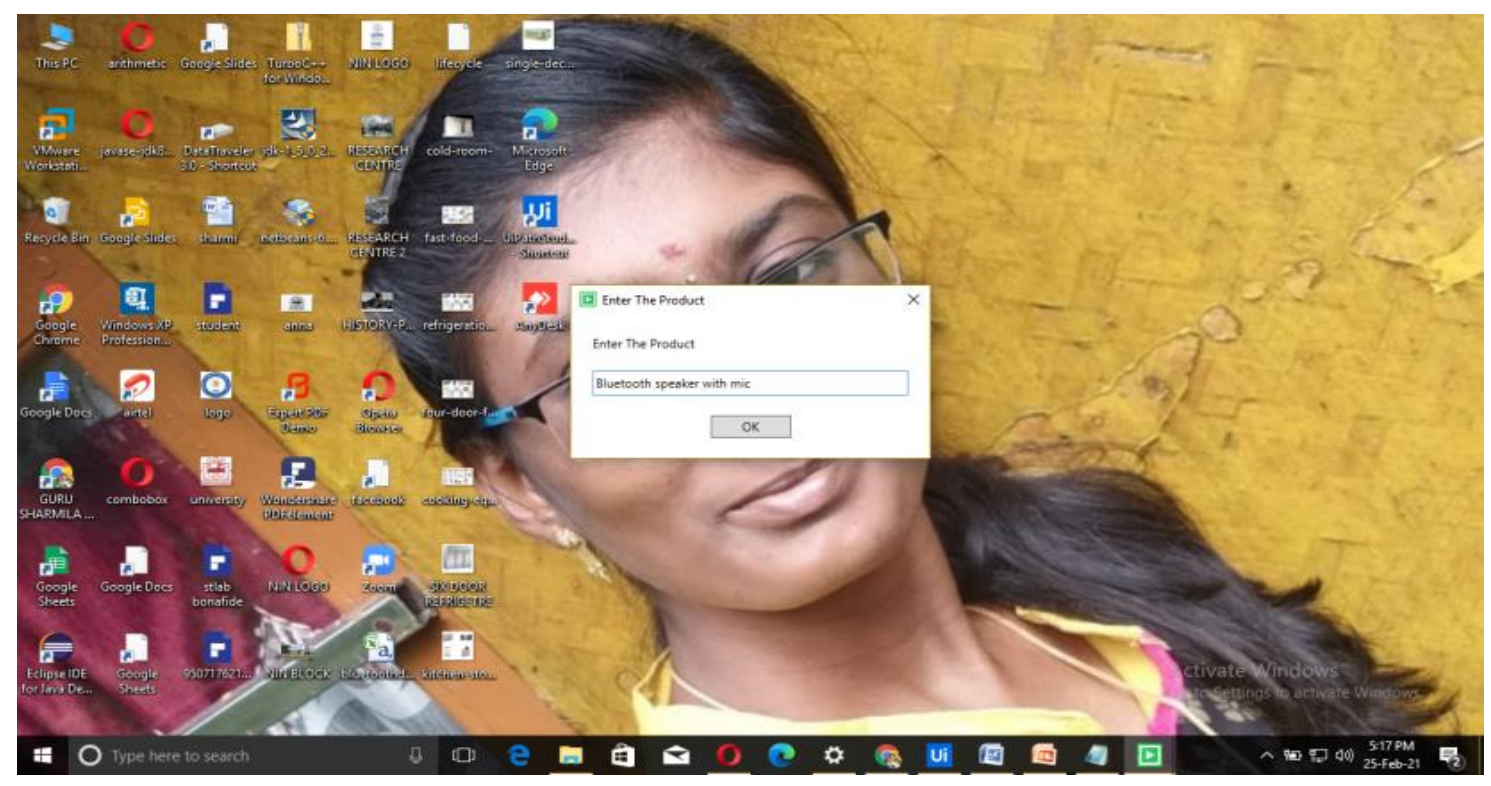

Figure 2 Purchase Form 


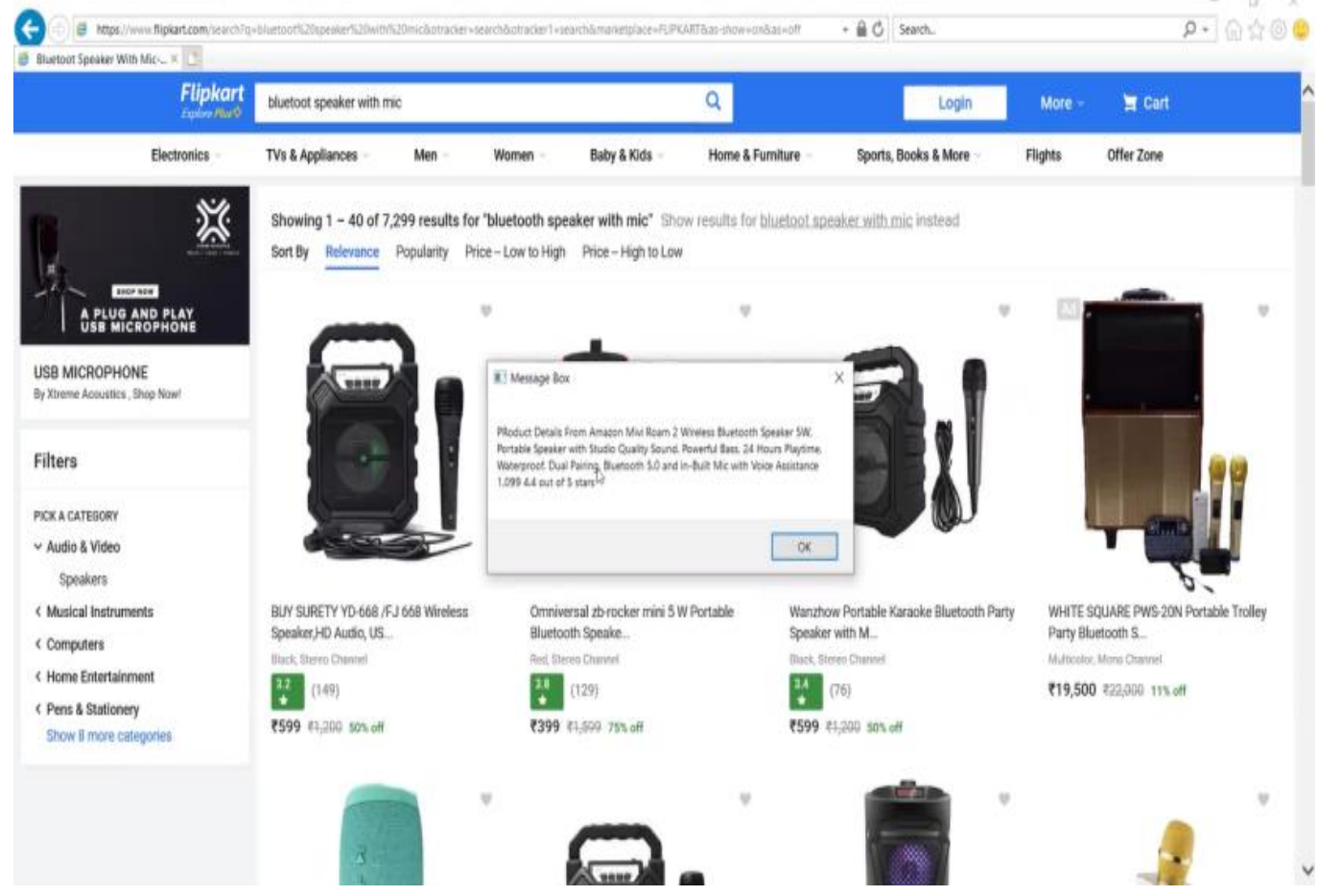

Figure 3 Amazon Result Form

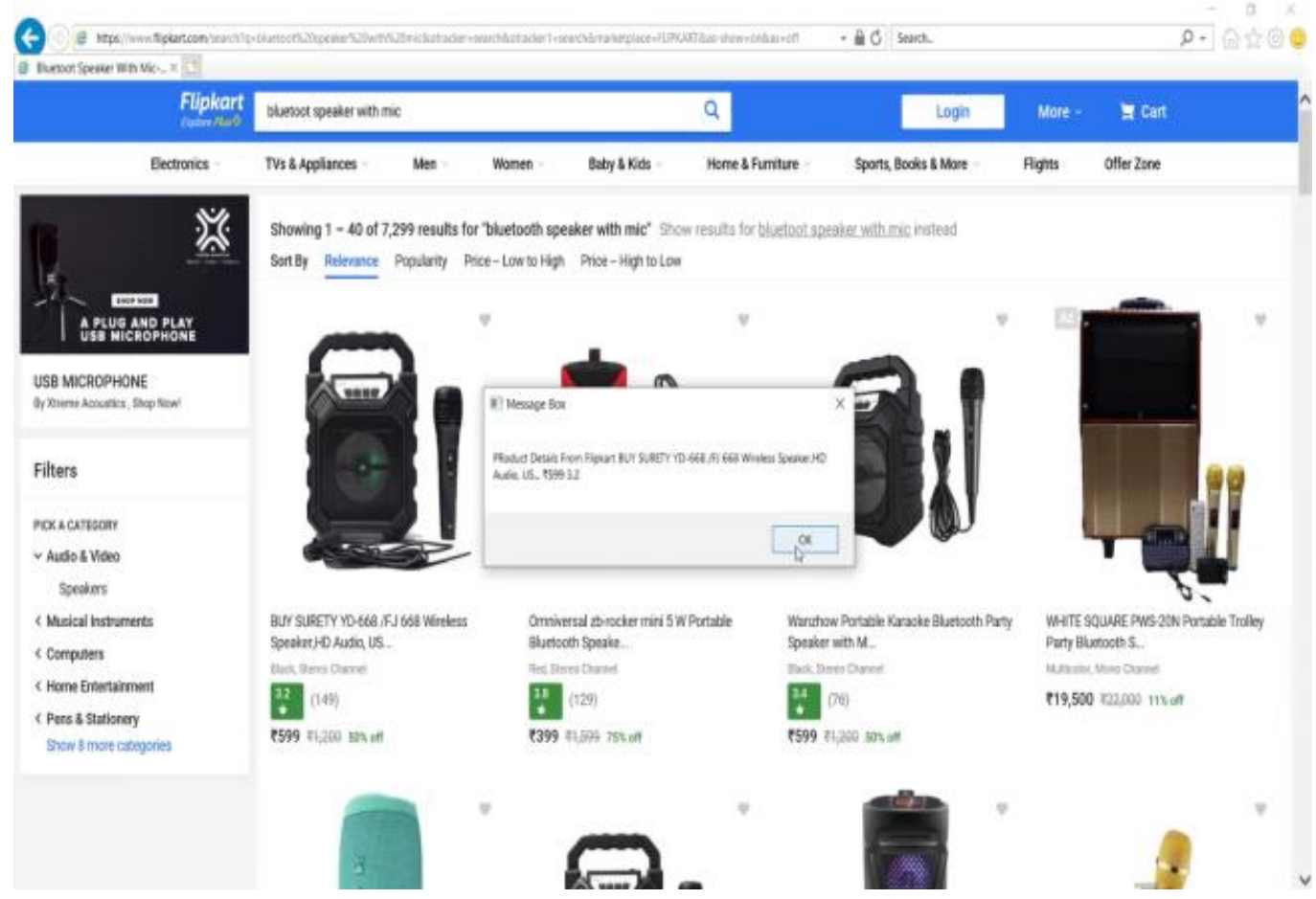

Figure 4 Flipkart Form 


\section{Performance analysis}

The exisiting and proposed system are analysed. The problem identified in exsiting The existing system is RPA is a tactical move to be used in the short term, until a traditional automation project can be planned and implemented. RPA is non-disruptive and is almost agnostic of the underlying technologies. The traditional automation of business processes (BPA) is a strategic information system transformation move, highlighting all of the places where existing processes can be automated with better system integration or the set-up of a specialized process software. it could be deployed on server or on user's desktop and it automates actions at the User Interface level. This assumption has prevented them from automating.Nearly $70 \%$ performance has been increased

\section{CONCLuSiON}

Robotic Process Automation technologies including manufacturing industries, chemical plants, the healthcare sector, aviation and so on, that were already discussed in this article. Let industry welcome the artificial intelligence humanoids to assist to human life. With this technology people will be improving their quality of life, caring of elderly people, get services in $24 \times 7$, escape the risky jobs from dangerous situations, bust workflow inefficiencies, shoring up productivity, and free people from doing repetitive tasks.

\section{FUTURE ENHANCEMENTS}

The irruption of the RPA tools in the analysis phase would offer an exceptional added value to the product, based on the fact to that exisisting proposals had not been able to integrate it until now and the analysis is one of the most important phases in a software project .Achieving substantial improvements in the execution of the analysis process when an RPA implementation project is carrying out means reducing economically and temporally the cost of the whole project .There after achieving the automation of this phase would be beneficial for the current offer of RPA,by incorporating additional interfaces that allow to document in detail the characteristics of each process to be automated ,including information such as objectives, metrics, deliverables, hypotheses, team members,scope,stake holders,customers, input data, and customer requirements.

\section{REFERENCES}

[1] Capgemini (2017). Robotic Process Automation: Gearing up for greater integration. White paper Available at: https://www.capgemini.com/wp-content/uploads/2017/08/robotic-process-autmoationpaper.pdf.

[2] A Study of Robotic Process Automation Among Artificial Intelligence — Available at: https://0x9.me/23EJU Robotic Process Automation. Available at: https://www.intellidynellc.com/sites/default/files/2019-02/ITD\%20RPA\%20Initiative.pdf.

[3] Maximizing Your RPA Available at: https://www.helpsystems.com/resources/guides/maximizing-roi-robotic-process-automation.

[4] Robotic Process Automation (2017). A Pragmatic Approach to Digital Transformation. White paper Available at: https://contextor.eu/wp-content/uploads/2017/06/Livre_Blanc_Contextor_EN.pdf.

[5] Dr. John Hindle, Dr. Mary Lacity, Dr. Leslie Willcocks, Dr. Shaji Khan (2018). ROBOTIC PROCESS AUTOMATION: Benchmarking the Client Experience. White paper Available at: https://0x9.me/GSzhj.

[6] Mark Davison and James Manos (2018). WHAT IS YOUR BOT VISION? when and How to Scale Robotic Process and Cognitive Automation. White paper Available at: https://0x9.me/CH6X1. 
[7] David Chappell (2017). Introducing Blue Prism. Robotic Process Automation for the Enterprise. White paper Available http://www.davidchappell.com/writing/white_papers/Introducing_Blue_Prism_v2--Chappell.pdf.

[8] Banks, M. R., Willoughby, L. M., \& Banks, W. A. (2008). Animal-assisted therapy and loneliness in nursing homes: use of robotic versus living dogs. Journal of the American Medical Directors Association, 9 (3), 173-177. [ Links ]

[9]. Barnett, G. (2015). Robotic process automation: adding to the process transformation toolkit. [ Links ]

[10]. Blue Prism Software Robots: Introducing the Virtual Workforce. Accessed dated on 12/6/2018 from the Accessed dated on 12/6/2018 from the https://www.blueprism.com/about-us . [ Links ]

\section{AUTHORS}

GuruSharmila S doing final year MCA in Francis Xavier Engineering College

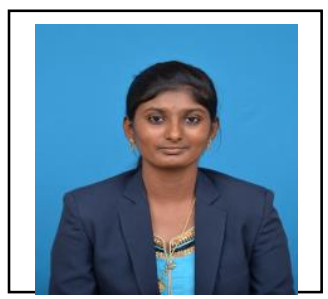

Mr. A. Arul Amalraj is working as Assistant Professor in the Department of Computer Applications, Francis Xavier Engineering College. He is having teaching experience of $12+$ years. His area of interest is Cloud Computing

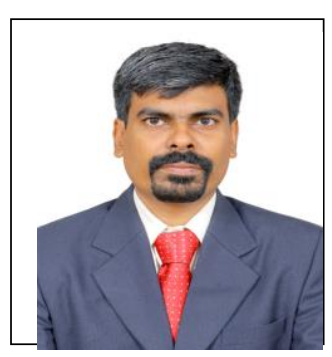

Subalakshmi K doing first year MCA in Francis Xavier Engineering College

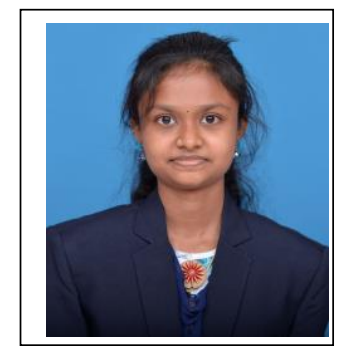

